\title{
The Protective Effect of Hesperidin on Methotrexate-Induced Intestinal Epithelial Damage in Rats: An Experimental Study
}

\author{
Can Acipayam ${ }^{a} \quad$ Ibrahim Bayram ${ }^{a}$ Kenan Daglioglu ${ }^{b}$ Figen Doran ${ }^{c}$ \\ Sema Yilmaz ${ }^{a}$ Gülay Sezgin ${ }^{a}$ Berna Totan Ateş ${ }^{c}$ Ayşe Ozkan ${ }^{a}$ Atila Tanyelia \\ ${ }^{a}$ Department of Pediatric Hematology/Oncology, ${ }^{\mathrm{b}}$ Medical and Experimental Research Center, and ${ }^{\mathrm{c}}$ Department of \\ Pathology, Faculty of Medicine, Cukurova University, Adana, Turkey
}

\section{Key Words}

Intestinal epithelial damage · Hesperidin · Inducible nitric oxide synthase $\cdot$ Methotrexate $\cdot$ Oxidative injury

\begin{abstract}
Objective: The purpose of this experimental study was to evaluate the efficacy of hesperidin (HES) in protecting against methotrexate (MTX)-induced intestinal damage using histopathological and immunohistochemical techniques. Materials and Methods: Seventy-eight male Wistar albino rats were divided into 4 groups that received (a) saline only (control group), $n=19$; (b) HES only, $n=19$; (c) MTX only, $n=19$, and (d) MTX plus HES, $n=21$. On the first day of the study, a single dose of MTX $(20 \mathrm{mg} / \mathrm{kg})$ was administered intraperitoneally to group 3 and 4 rats. The HES $(200 \mathrm{mg} / \mathrm{kg})$ was administered by gavage for 5 days. For the MTX plus HES group, HES ( $200 \mathrm{mg} / \mathrm{kg}$ ) was administered by gavage for 5 days after MTX treatment. Rats were sacrificed on the 2 nd, 4 th and 6th day of the study. Tissue samples from the jejunum were taken for histopathological and immunohistochemical analysis. Results: On the 4th day, crypt injury in the MTX plus HES group $(1.00 \pm 0.00)$ was less than that in the MTX group $(2.00 \pm 0.89 ; p<0.05)$. The small intestinal damage score was lower in the MTX plus HES group $(6.33 \pm 0.82)$
\end{abstract}

\begin{tabular}{ll}
\hline KARGER & $\begin{array}{l}\text { ( } 2013 \text { S. Karger AG, Basel } \\
1011-7571 / 14 / 0231-0045 \$ 39.50 / 0\end{array}$ \\
$\begin{array}{l}\text { E-Mail karger@karger.com } \\
\text { www.karger.com/mpp }\end{array}$ & $\begin{array}{l}\text { This is an Open Access article licensed under the terms of the } \\
\text { Creative Commons Attribution-NonCommercial 3.0 Un- } \\
\text { ported license (CC BY-NC) (www.karger.com/OA-license), } \\
\text { applicable to the online version of the article only. Distribu- } \\
\text { tion permitted for non-commercial purposes only. }\end{array}$
\end{tabular}

as compared to the MTX group $(8.00 \pm 2.37)$. Inducible nitric oxide synthase and interleukin-8 levels were lower in the MTX plus HES group ( 65 and $25 \%$, respectively) as compared to the corresponding values of the MTX group (80 and 52.5\%, respectively). On the 6 th day, the Ki- 67 proliferation index in the MTX group (45\%) was lower than that in the MTX plus HES group $(76.67 \%)$ and the control group $(p<0.05)$. The small intestinal damage score was high in the HES group on the 4th day due to increased cellular infiltration. On the 6th day, the Ki-67 proliferation index rose in parallel with the decrease in cellular infiltration and therefore histopathological scoring. The proliferation-enhancing effect of HES also appeared in healthy rats. Conclusion: HES seemed to have a protective effect against MTX-induced intestinal injury.

(c) 2013 S. Karger AG, Basel

\section{Introduction}

Methotrexate (MTX) is a folate antagonist originally developed for the treatment of malignancies [1]. It inhibits dihydrofolate reductase, which is an essential enzyme for DNA and RNA synthesis. One of the most common limiting factors preventing further dose escalation of MTX is gastrointestinal toxicity [2-4]. Damage to the 
gastrointestinal epithelium after MTX chemotherapy includes villus shortening and fusion, epithelial atrophy, crypt loss, inflammatory infiltrate in the lamina propria, goblet cell depletion and loss of mucosal integrity [5]. Several studies aiming to prevent MTX-induced damage using antioxidant agents such as ozone, $\mathrm{N}$-acetylcysteine, lactoferrin, melatonin, prostaglandin E, garlic extract and vitamin A have reported beneficial effects [5-11].

Hesperidin (HES) is a flavanone glycoside mainly found in citrus fruits. HES has been reported to exhibit anti-inflammatory, antimicrobial, anticarcinogenic and antioxidant effects, and to reduce capillary fragility [12]. It has also been reported to have hypolipidemic effects [13] and to exhibit analgesic activity [14], colony stimulating factor-inducing activity [15], nitric oxide (NO) synthase inhibition [16] and antiapoptotic efficacy [17]. Experiments have shown that HES is nontoxic, easily assimilated, has nonaccumulative effects and does not cause any allergic reactions in male or female mice [18].

The purpose of this experimental study was to evaluate the efficacy of HES in protecting against MTX-induced intestinal damage using histopathological and immunohistochemical techniques.

\section{Materials and Methods}

\section{Experimental Model}

Seventy-eight 16-week-old male Wistar albino rats weighing $275-420 \mathrm{~g}$ were used. Rats were housed 6 or 7 in a cage and maintained on a 12-hour light/dark cycle at a constant temperature of $21 \pm 2{ }^{\circ} \mathrm{C}$ and a relative humidity of $40-60 \%$. All animals were weighed initially and before sacrifice, and their weights were recorded. Rats were divided into 4 groups that received (a) saline only, $\mathrm{n}=19$; (b) HES only, $\mathrm{n}=19$; (c) MTX only, $\mathrm{n}=19$, and (d) MTX plus HES, $n=21$. All experimental protocols were approved by the Committee on Animal Research at Cukurova University, Turkey. Experimental animals were cared for and used in accordance with the National Institute of Health guidelines.

\section{Study Protocol}

For the saline-only group (control), isotonic saline was administered orally through an intragastric tube for 5 days.

For the HES group, HES (Sigma Chemical, Co., St. Louis, Mo., USA) was dissolved in distilled water and administered orally at a dose of $200 \mathrm{mg} / \mathrm{kg}$ through an intragastric tube for 5 days, and continued until rats were sacrificed.

For the MTX group, a single dose $(20 \mathrm{mg} / \mathrm{kg})$ of MTX (MTX $500 \mathrm{mg} / 20 \mathrm{ml}$; F.H. Faulding \& Co. Ltd., Mulgrave, Vic., Australia) was administered intraperitoneally to each rat. Serum saline was given as a placebo through an intragastric tube 5 days after MTX injection and continued daily until the rats were sacrificed.

For the MTX plus HES group, 5 days after the administration of a single intraperitoneal dose of MTX $(20 \mathrm{mg} / \mathrm{kg})$, HES was dissolved in distilled water, administered orally at a dose of $200 \mathrm{mg} /$ kg through an intragastric tube every day and continued until the rats were sacrificed.

All rats were sacrificed using intraperitoneal ketamine hydrochloride (50 mg/kg; Ketalar; Parke Davis and Eczacıbaşı, Istanbul, Turkey) and xylazine hydrochloride (5 mg/kg; Rompun; Bayer HealthCare, Istanbul, Turkey) injection on either the 2nd, 4th or 6 th day. Six rats from the control, HES and MTX groups were sacrificed on the 2 nd and 4 th day, and 7 on the 6th day. In the MTX plus HES group, 6 rats were sacrificed on the 2 nd and 4 th day, and 9 rats on the 6th day. Jejunum tissue samples $(0.5 \mathrm{~cm})$ were removed $5 \mathrm{~cm}$ from the proximal end for histopathological examination and immunohistochemical analysis.

\section{Histopathology}

Jejunum tissue samples were fixed in $10 \%$ neutral formalin, embedded in paraffin and cut with a microtome set at a thickness of $5 \mu \mathrm{m}$. Tissue sections were stained with hematoxylin and eosin (HE) and examined under a light microscope. HE-stained tissue sections were examined for villus damage, crypt damage, goblet cell depletion and mononuclear cell infiltration in the lamina propria. The appearance of all groups was scored by a single observer (F.D.) blinded to type of treatment as follows: no lesion $=0$; mild damage $=1$; moderate damage $=2$, and severe damage $=3$. Goblet cell numbers were scored as follows: $0-49$ cells $=$ $3 ; 50-99$ cells $=2 ; 100-149$ cells $=1$, and $\geq 150$ cells $=0$. Total small intestinal damage score was then calculated [11]. The intestinal damage scores of the groups were determined by totaling the villous damage, crypt damage, goblet cell depletion and cellular infiltration scores.

\section{Immunohistochemistry}

The following primary antibodies were used for immunohistochemical analysis: Ki-67 antigen mouse monoclonal antibody, inducible NO synthase (iNOS) rabbit primary antibody, myeloperoxidase (MPO) primary antibody and interleukin-8 (IL-8) rabbit primary antibody (all from Dakocytomation, Inc. Biotinylated Link Universal, North America, USA). Ki-67, iNOS, MPO and IL-8 immunohistochemical analyses were performed using the streptavidin-biotin-peroxidase method. All sections were dewaxed, rehydrated, rinsed with Tris-buffered saline (TBS; pH 7.6), treated with $3 \%$ hydrogen peroxide and rinsed again with TBS. Tissue sections were immersed in citrate buffer ( $\mathrm{pH}$ 6.0) and autoclaved for $15 \mathrm{~min}$ to retrieve antigen. Samples were kept for approximately $45 \mathrm{~min}$, without opening the lid, to reach room temperature. Primary antibodies were subsequently 'dropped' and kept in a closed and moist environment for $1.5-2 \mathrm{~h}$. After a further wash with TBS, the slides were counterstained with Mayer's hematoxylin. Semiquantitative analysis was performed by counting the Ki-67, iNOS, MPO and IL-8 antigen-positive cells per field under a light microscope. The mean number of such cells in 100 randomly selected fields in each small intestine was expressed as the number of Ki-67, iNOS, MPO and IL-8 antigen-positive cells [1921].

\section{Statistical Analysis}

Values are presented as the means \pm standard deviation. Analysis of both weight loss and histopathological data was performed using SPSS-15. The Mann-Whitney U test was used to compare the results obtained from the 4 groups; $\mathrm{p}<0.05$ was regarded as statistically significant. 
Table 1. Weight loss in experimental animals following treatment with MTX alone or MTX plus HES

\begin{tabular}{lccc}
\hline & Day 2 & Day 4 & Day 6 \\
\hline Weight loss, $g(\%)$ & & & \\
Control group & $6.71 \pm 7.11(2)$ & $9.57 \pm 18.65(3)$ & $2.43 \pm 5.59(0.8)$ \\
HES group & $16.43 \pm 14.35(4.6)$ & $20.00 \pm 21.41(5.6)$ & $11.43 \pm 12.49(3.2)$ \\
MTX group & $23.57 \pm 23.04(6.3)$ & $27.14 \pm 17.04(7.3)^{\mathrm{a}}$ & $43.57 \pm 34.36(11.8)^{\mathrm{a}}$ \\
MTX plus HES group & $15.43 \pm 20.07(4.0)$ & $32.14 \pm 18.89(8.3)^{\mathrm{a}}$ & $34.29 \pm 27.29(8.9)^{\mathrm{a}}$ \\
\hline
\end{tabular}

a Statistically significant at $\mathrm{p}<0.05$ as compared to control group.

Table 2. Scores of the small intestine of rats on days 2, 4 and 6 following treatment with MTX alone or MTX plus HES

\begin{tabular}{llccc}
\hline Parameter & $\begin{array}{l}\text { Control group } \\
(\mathrm{n}=19)\end{array}$ & $\begin{array}{l}\text { HES group } \\
(\mathrm{n}=19)\end{array}$ & $\begin{array}{l}\text { MTX group } \\
(\mathrm{n}=19)\end{array}$ & $\begin{array}{l}\text { MTX plus HES group } \\
(\mathrm{n}=21)\end{array}$ \\
\hline Day 2 & & & & \\
$\quad$ Villus damage & $0.33 \pm 0.52$ & $0.17 \pm 0.41$ & $1.17 \pm 0.41^{\mathrm{a}}$ & $0.83 \pm 0.41$ \\
$\quad$ Crypt damage & $0.17 \pm 0.41$ & $0.00 \pm 0.00$ & $0.5 \pm 0.84$ & $0.83 \pm 0.98$ \\
$\quad$ Cellular infiltration & $0.00 \pm 0.00$ & $0.67 \pm 0.52$ & $1.33 \pm 0.52^{\mathrm{a}}$ & $1.33 \pm 0.52^{\mathrm{a}}$ \\
$\quad$ Goblet cell depletion & $0.00 \pm 0.00$ & $0.00 \pm 0.00$ & $0.50 \pm 0.55$ & $0.17 \pm 0.41$ \\
$\quad$ Total small intestinal damage score & $0.33 \pm 0.52$ & $0.83 \pm 0.75$ & $3.50 \pm 1.98^{\mathrm{a}}$ & $3.17 \pm 1.47^{\mathrm{a}}$ \\
Day 4 & & & & \\
$\quad$ Villus damage & $0.17 \pm 0.41$ & $1.00 \pm 0.00$ & $2.17 \pm 0.75^{\mathrm{a}}$ & $1.67 \pm 0.52^{\mathrm{a}}$ \\
$\quad$ Crypt damage & $0.00 \pm 0.00$ & $1.00 \pm 0.00$ & $2.00 \pm 0.89^{\mathrm{a}}$ & $1.00 \pm 0.00^{\mathrm{a}} \mathrm{b}$ \\
$\quad$ Cellular infiltration & $0.00 \pm 0.00$ & $2.00 \pm 0.00$ & $1.83 \pm 0.41^{\mathrm{a}}$ & $1.50 \pm 0.55^{\mathrm{a}}$ \\
$\quad$ Goblet cell depletion & $0.00 \pm 0.00$ & $0.00 \pm 0.00$ & $2.00 \pm 0.63^{\mathrm{a}}$ & $2.00 \pm 0.00^{\mathrm{a}}$ \\
$\quad$ Total small intestinal damage score & $0.17 \pm 0.41$ & $4.00 \pm 0.00$ & $8.00 \pm 2.37^{\mathrm{a}}$ & $6.33 \pm 0.82^{\mathrm{a}}$ \\
Day 6 & & & & \\
$\quad$ Villus damage & $0.14 \pm 0.38$ & $0.57 \pm 0.53$ & $1.14 \pm 0.69^{\mathrm{a}}$ & $0.56 \pm 0.53$ \\
$\quad$ Crypt damage & $0.00 \pm 0.00$ & $0.29 \pm 0.49$ & $0.14 \pm 0.38$ & $0.22 \pm 0.44$ \\
$\quad$ Cellular infiltration & $0.14 \pm 0.38$ & $1.00 \pm 0.58$ & $1.14 \pm 0.38^{\mathrm{a}}$ & $1.11 \pm 0.33^{\mathrm{a}}$ \\
$\quad$ Goblet cell depletion & $0.00 \pm 0.00$ & $0.00 \pm 0.00$ & $0.57 \pm 0.53^{\mathrm{a}}$ & $0.11 \pm 0.33$ \\
$\quad$ Total small intestinal damage score & $0.29 \pm 0.49$ & $1.86 \pm 1.22$ & $3.00 \pm 1.53^{\mathrm{a}}$ & $2.00 \pm 0.87^{\mathrm{a}}$ \\
\hline
\end{tabular}

Data are arithmetical means \pm SD. ${ }^{\text {a }}$ Statistically significant at $\mathrm{p}<0.05$ as compared to control group. ${ }^{\mathrm{b}}$ Statistically significant at $\mathrm{p}<0.05$ as compared to MTX group.

\section{Results}

There was no significant weight loss in the rats of the control group. The rats treated with MTX alone lost more weight than those treated with MTX plus HES on the days of sacrifice. The differences in weight loss between the control group and the rats treated with MTX alone and those treated with MTX plus HES were statistically significant; $\mathrm{p}$ values for days 4 and 6 were $\mathrm{p}<0.05$. The weight loss in the MTX plus HES-treated rats was less than that in the MTX-treated rats on day 6 (table 1). Although weight loss in the HES group was greater than in the control group, no statistically significant difference was observed on the $2 \mathrm{nd}, 4$ th and 6 th day $(\mathrm{p}>0.05)$. Daily food intake in the HES group was similar to that of the control group. No diarrhea was seen in the HES group. The rats treated with MTX alone became exhausted and grossly emaciated. They more frequently developed diarrhea compared to the rats treated with MTX plus HES. This was only evaluated subjectively.

\section{Histopathological Findings}

The villus damage, crypt damage, inflammatory cellular infiltration and goblet cell numbers in the tissue samples from the control and experimental groups are expressed as total intestinal damage scores in table 2 . The 
Fig. 1. Pathological images of jejunal injury in the groups on the 4th day. a Control group: normal jejunal tissue. b HES group. c MTX group: villus atrophy, necrosis, decreased number of epithelial cells and an atrophic appearance in basal crypts, pronounced cellular infiltration. d MTX plus HES group: villus atrophy, villus damage, necrosis and flattening. HE, $\times 200$. Thick white arrows = Villus; thick black arrows $=$ crypt; thin black arrows = goblet cells.
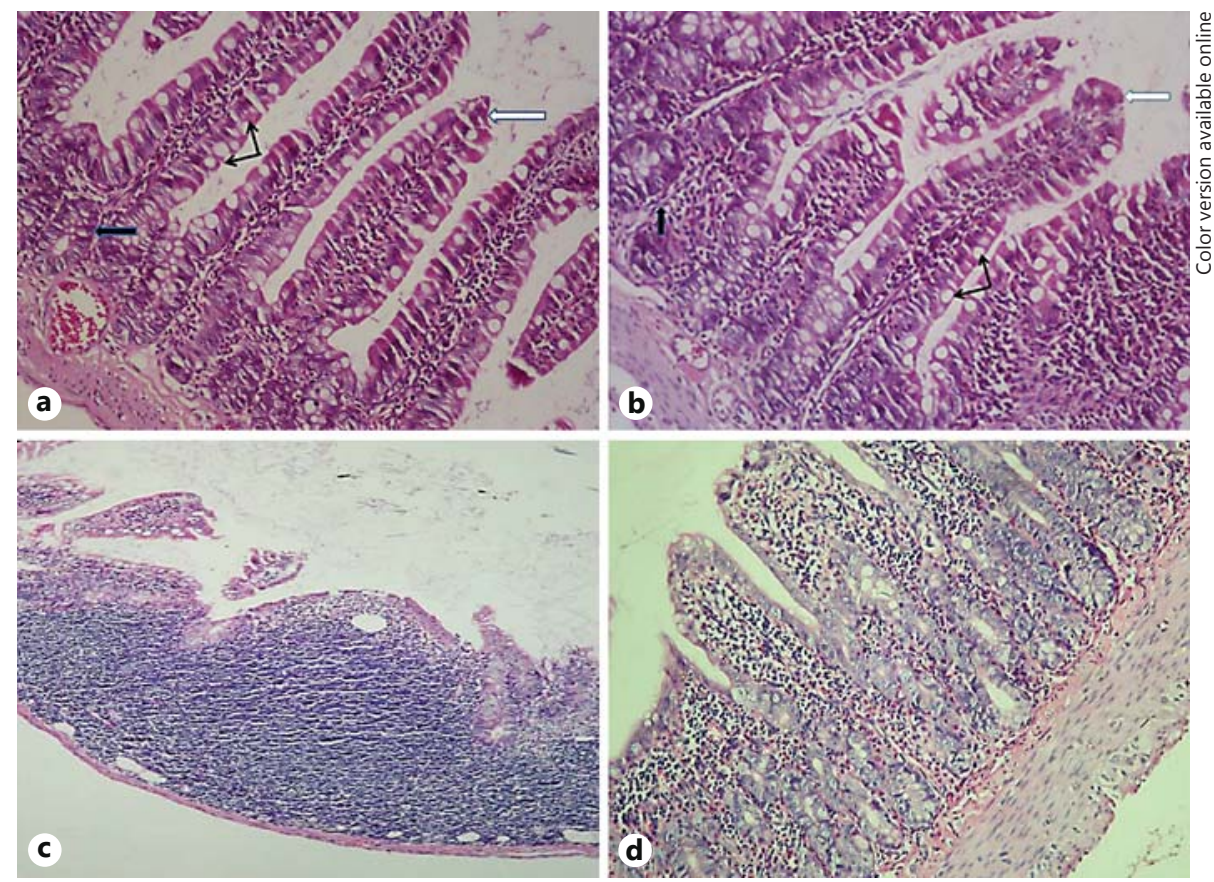

tissue sections of the rats in the control group exhibited a normal intestinal structure (fig. 1).

On day 2, the tissue sections of the rats treated with MTX showed greater villus shortening and fusion ( $\mathrm{p}=$ 0.018 ) compared to the control group, as well as inflammatory infiltrate in the lamina propria $(\mathrm{p}=0.002)$. Although villus damage, goblet cell depletion and total jejunal damage scores were lower in the MTX plus HES group compared to the MTX group on day 2, the differences between the 2 groups were not significant.

On the 4th day, there was pronounced small intestinal damage, and the histopathological findings were more severe than those on the 2nd day in the MTX-treated group and MTX plus HES-treated group (fig. 1). The difference in crypt damage between the rats treated with MTX alone and those treated with MTX plus HES was statistically significant; the $\mathrm{p}$ value for day 4 was $\mathrm{p}=0.022$. Although villus damage and cellular infiltration were lower in the MTX plus HES group than in the MTX group, the difference was not statistically significant. Goblet cell depletion levels were similar in both groups.

On the 6th day, villus height was increased, and despite epithelial cell degeneration, there was also an increase in regeneration in the MTX-treated group and the MTX plus HES-treated group. The total score for small intestinal damage in the MTX-treated group was higher than that in the MTX plus HES-treated group on the 6th day.
Villus damage and goblet cell depletion in the MTX-treated group were higher than those in the MTX plus HEStreated group on the 6th day. However, the difference was not statistically significant. Although the histopathological findings in the MTX and MTX plus HES groups were similar on the 4th day, when damage was greatest, the total small intestinal damage score was lower in the MTX plus HES group for all days, as outlined in table 2.

\section{Immunohistochemical Findings}

Immunohistochemistry results of the small intestine of control and experimental groups are expressed in table 3. The number of cells staining positive for iNOS and IL-8 in the MTX group showed a tendency to rise in comparison with the MTX plus HES group on the 2nd day, but the differences between the two groups were not significant ( $p>0.05)$. A similar number of Ki-67 antigen-positive cells was found in the MTX-treated rats and the MTX plus HES-treated rats on the 2 nd day (table 3 ).

Maximal damage to the small intestine was seen on the 4th day.

The number of Ki-67 antigen-positive cells was lower in the MTX-treated rats than in the MTX plus HES-treated rats. The number of iNOS and IL-8 immunostaining cells in the MTX group showed a tendency to rise in comparison with the MTX plus HES group on the 4th day $(\mathrm{p}=0.019$ and $\mathrm{p}=0.036$; fig. 2$)$.
48

Med Princ Pract 2014;23:45-52 DOI: $10.1159 / 000355900$
Acipayam et al. 
Fig. 2. Pathological images of iNOS activity in the groups on the 4th day. a Control group. b HES group. c MTX group: increased iNOS activity. d MTX plus HES group. iNOS staining, $\times 200$.
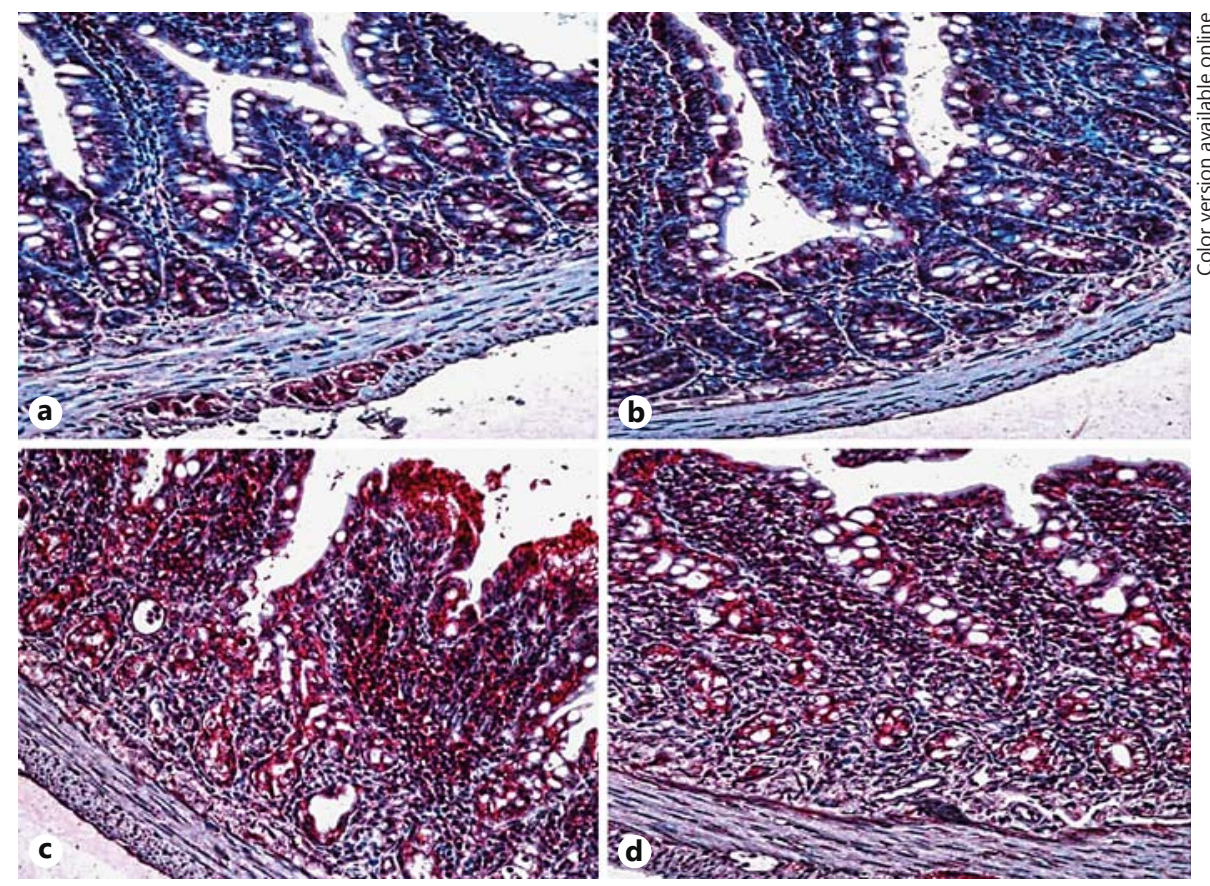

Table 3. Immunohistochemistry results of the small intestine of rats on days 2, 4 and 6 following treatment with MTX alone or MTX plus HES

\begin{tabular}{lcccc}
\hline Parameter & $\begin{array}{l}\text { Control group } \\
(\mathrm{n}=19)\end{array}$ & $\begin{array}{l}\text { HES group } \\
(\mathrm{n}=19)\end{array}$ & $\begin{array}{l}\text { MTX group } \\
(\mathrm{n}=19)\end{array}$ & $\begin{array}{l}\text { MTX plus HES } \\
\text { group } \\
(\mathrm{n}=21)\end{array}$ \\
\hline Day 2,\% & & & & \\
iNOS antigen-positive cell rate & $57.83 \pm 13.6$ & $77.50 \pm 6.12$ & $76.50 \pm 16.66^{\mathrm{a}}$ & $66.67 \pm 5.16$ \\
MPO antigen-positive cell rate & $0.00 \pm 0.00$ & $0.00 \pm 0.00$ & $16.33 \pm 25.30$ & $3.33 \pm 5.16$ \\
IL-8 antigen-positive cell rate & $48.33 \pm 1.63$ & $63.33 \pm 22.51$ & $69.83 \pm 12.97^{\mathrm{a}}$ & $57.83 \pm 10.34^{\mathrm{a}}$ \\
Ki-67 antigen-positive cell rate & $49.00 \pm 0.00$ & $83.33 \pm 13.66$ & $6.33 \pm 4.68^{\mathrm{a}}$ & $8.67 \pm 9.52^{\mathrm{a}}$ \\
Day 4,\% & & & & \\
iNOS antigen-positive cell rate & $63.33 \pm 12.11$ & $68.33 \pm 17.22$ & $80.00 \pm 10.95^{\mathrm{a}}$ & $65.00 \pm 5.48^{\mathrm{b}}$ \\
MPO antigen-positive cell rate & $0.00 \pm 0.00$ & $0.00 \pm 0.00$ & $1.67 \pm 4.08$ & $1.67 \pm 4.08$ \\
IL-8 antigen-positive cell rate & $54.16 \pm 12.68$ & $23.33 \pm 10.33$ & $52.50 \pm 8.57$ & $25.00 \pm 23.45^{\mathrm{a}, \mathrm{b}}$ \\
Ki-67 antigen-positive cell rate & $55.50 \pm 20.23$ & $83.33 \pm 8.16$ & $27.17 \pm 30.27$ & $58.17 \pm 16.13$ \\
Day 6, \% & & & & $56.67 \pm 20.00$ \\
iNOS antigen-positive cell rate & $61.00 \pm 11.22$ & $55.57 \pm 27.03$ & $50.86 \pm 16.83$ & $0.00 \pm 0.00$ \\
MPO antigen-positive cell rate & $0.00 \pm 0.00$ & $0.00 \pm 0.00$ & $7.00 \pm 18.52$ & $70.00 \pm 12.25^{\mathrm{a}, \mathrm{b}}$ \\
IL-8 antigen-positive cell rate & $46.29 \pm 7.18$ & $45.71 \pm 29.36$ & $35.00 \pm 23.91$ & $76.67 \pm 17.32^{\mathrm{a}, \mathrm{b}}$ \\
Ki-67 antigen-positive cell rate & $50.71 \pm 9.14$ & $75.57 \pm 16.45$ & $45.00 \pm 7.42$ & \\
\hline
\end{tabular}

Data are arithmetical means $\pm \mathrm{SD}$. a Statistically significant at $\mathrm{p}<0.05$ as compared to control group. ${ }^{\mathrm{b}}$ Statistically significant at $\mathrm{p}<0.05$ as compared to MTX group.

Effect of Hesperidin on MTX-Induced Intestinal Epithelial Damage
Med Princ Pract 2014;23:45-52 DOI: $10.1159 / 000355900$ 
Fig. 3. Pathological images of Ki-67 proliferation in the groups on the 6th day. a Control group: normal jejunal tissue. b HES group. c MTX group. d MTX plus HES group: increased Ki-67 proliferation index. Ki-67 staining, $\times 200$.
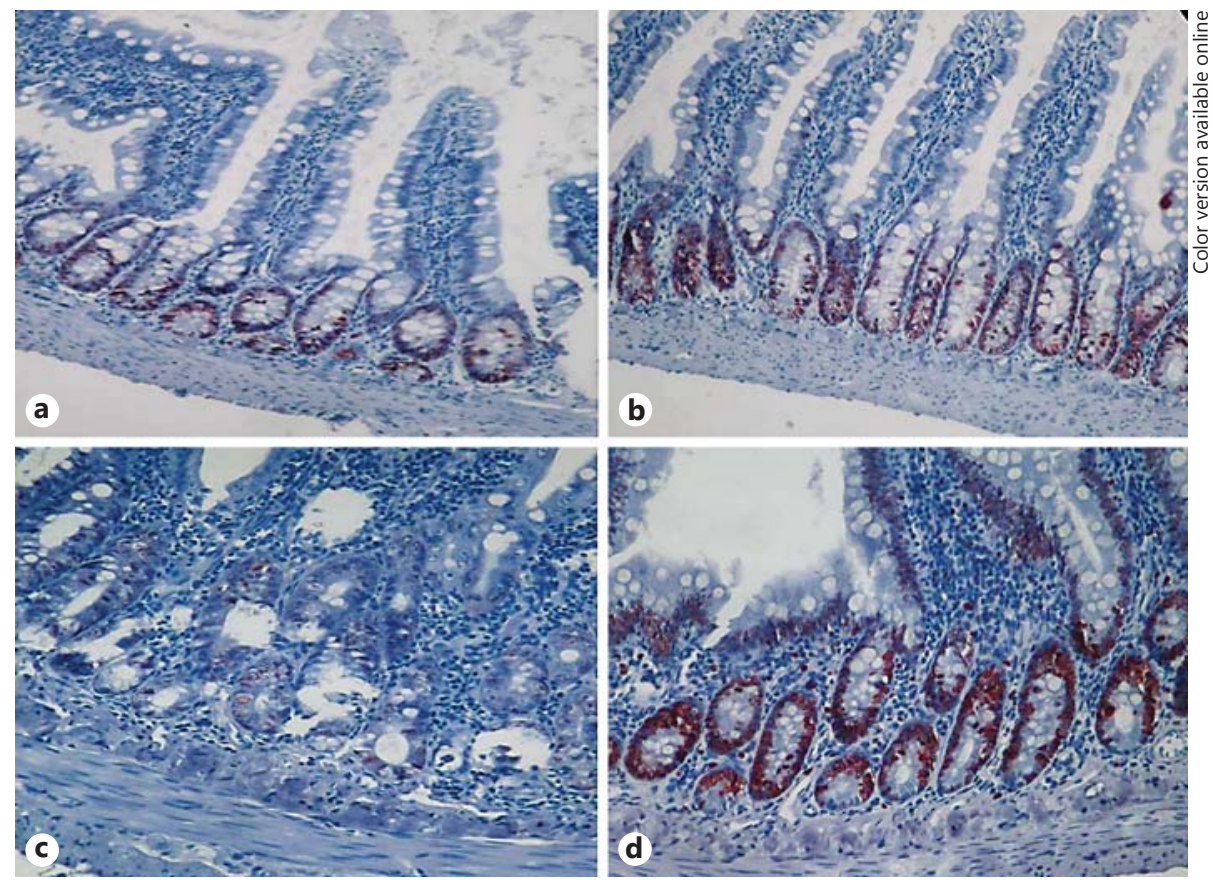

The MPO activity in the small intestinal segment was similar in the MTX-treated group compared to the MTX plus HES-treated group.

On the 6th day, jejunum crypt cell proliferation, illustrated by the number of Ki-67 antigen-positive cells, increased in the MTX plus HES group compared to the MTX group (fig. 3). Treatment with MTX plus HES significantly $(p=0.005)$ increased the number of Ki-67-positive cells. The number of IL-8 immunostaining cells in the MTX plus HES group rose in comparison with the control group on the 6th day $(p=0.001)$. Although MPO activity was increased by the treatment with MTX alone in the small intestinal segment in comparison with the MTX plus HES group, the difference was not statistically significant.

\section{Discussion}

While iNOS and IL-8 values in the MTX group were higher on the 4 th day, when damage was greatest, these values decreased with the addition of HES. Ki-67 values showing tissue proliferation were significantly higher in the MTX plus HES group compared to the MTX group on the 6th day, thus indicating that MTX-induced injury in the intestine was ameliorated by HES treatment. The general characteristics (villus atrophy, crypt loss and gob- let cell depletion) of MTX-induced small intestinal mucositis were the same in our study as described previously $[11,22]$.

Reactive oxygen species (ROS) are believed to play an important role in the pathogenesis of MTX-induced intestinal damage. MTX increases cytosolic peroxide and decreased cellular levels of the antioxidant glutathione (GSH) $[5,23]$. MTX increases malondialdehyde (MDA) and MPO activities and collagen content and reduces GSH levels in the ileum, liver and kidney [3]. The significant reduction in GSH levels produced by MTX leads to a reduction in effectiveness of the antioxidant enzyme defense system, sensitizing the cells to ROS [24].

HES has been reported to have antioxidant properties, which may play an important role in the prevention of anticancer drug-induced toxicity in cells. Soares et al. [2] demonstrated that oxidative stress and neutrophil infiltration play an important role in MTX-induced small intestinal damage in rats. They observed an increase in MPO activity in all intestinal segments, followed by a recovery, revealing the possible participation of neutrophil infiltration in MTX-induced intestinal mucositis. Although there was an increase in MPO activity in the jejunal tissue associated with MTX treatment, this was not significant. Our results are in accordance with these findings. Our findings show MTX-induced intestinal injury via the accumulation of activated neutrophils. 
Ki-67 is a nuclear protein present in multiplying cells. With immunohistochemical techniques, the percentage of cells showing Ki-67-positive immunostaining indicates the proliferation index [25]. Leitão et al. [20] demonstrated that MTX significantly reduced the number of Ki-67-positive cells, indicating a reduction in proliferation. Our results are in accordance with these findings in the literature. HES administration restored the Ki67-positive rate lowered by MTX injection.

Recent evidence suggests that NO plays a regulatory role in gut barrier function. Studies have shown that the localized production of $\mathrm{NO}$ by villus enterocytes can result in an increase in enterocyte apoptosis. The mechanism of pathogenesis of this damage is not clear. However, excess NO production has been implicated in the loss of barrier function [26]. NO has been shown to be an important mediator of MTX-induced oral mucositis, suggesting that chemotherapy-induced iNOS activation may play a critical role in mucosal injury. iNOS immunostaining was particularly noticeable in neutrophils inside and surrounding the necrotic crypt. This suggests that NO produced by these cells is involved in the mucosal damage [20]. Leitão et al. [20] demonstrated increased iNOS expression in jejunal samples revealed by immunohistochemistry, following treatment with MTX. We detected a significant increase in iNOS immunostaining in the jejunal tissue of rats on the 4th day of the MTX-induced intestinal mucositis. Sakata et al. [27] also reported that HES inhibits iNOS in a mouse macrophage cell line. We observed that the protective effects of HES were associated with reduced neutrophil infiltration, suggesting that NO synthesis inhibition may lead to poor neutrophil infiltration. iNOS levels were higher in the MTX group compared to the MTX plus HES group on the 4th day, when jejunal damage was greatest $(p=0.019)$.

IL-8 is a member of the chemokine family. It is a major chemotactic and activating peptide for neutrophils. It stimulates neutrophil movement, direct migration, adherence to the molecular surface, enzyme release and the production of free oxygen radical metabolites. Experimental studies have shown that IL-8 levels in the intesti- nal epithelium are increased by chemotherapeutic agents [28]. Several studies have shown that HES reduces IL-8 expression $[29,30]$. We demonstrated greater neutrophil infiltration in the lamina propria and more intensive staining with IL-8 in the MTX group compared to the MTX plus HES group on the 4th day, when intestinal damage in rats was greatest. The highest staining with IL-8 among the study groups on the 4th day was seen in the MTX plus HES group. Interestingly, on the 6th day, there was a pronounced rise in the IL- 8 antigen-positive cell level in the MTX plus HES group. This may be attributed to the excessive release of IL-8, a proinflammatory cytokine, parallel to an increase in cell proliferation and inflammatory cells under the influence of HES. Further studies are now needed on this subject.

\section{Conclusion}

MPO immunostaining was most pronounced in the MTX group. iNOS and IL-8 immunostaining were highest in the MTX group on the 4th day, when intestinal injury was greatest. Ki-67 immunostaining showing intestinal proliferation was lowest in the MTX group but increased significantly in the HES group, thereby indicating that HES increased proliferation. The present study showed that HES was effective in reducing the intensity of small intestinal damage induced by MTX. It is probable that this protective effect of HES may prove useful in clinical practice to prevent intestinal epithelial injury resulting from MTX treatment.

\section{Acknowledgement}

This work was supported by the Cukurova University Research (TF2010LTP45) Fund.

\section{Disclosure Statement}

There are no conflicts of interest.

\section{References}

Effect of Hesperidin on MTX-Induced

Intestinal Epithelial Damage
Med Princ Pract 2014;23:45-52 DOI: $10.1159 / 000355900$
- 3 Sener G, Ekșioğlu-Demiralp E, Cetiner M, et al: L-Carnitine ameliorates methotrexate-induced oxidative organ injury and inhibits leukocyte death. Cell Biol Toxicol 2006;22:47-60. munopharmacology 2000;47:247-257.

2 Soares PM, Lopes LO, Mota JM, et al: Methotrexate-induced intestinal mucositis delays gastric emptying and gastrointestinal transit of liquids in awake rats. Arq Gastroenterol 2011;48:80-85.
4 Carneiro-Filho BA, Lima IP, Araujo DH, et al: Intestinal barrier function and secretion in methotrexate-induced rat intestinal mucositis. Dig Dis Sci 2004;49:65-72. 
5 Kesik V, Uysal B, Kurt B, et al: Ozone ameliorates methotrexate-induced intestinal injury in rats. Cancer Biol Ther 2009;8:1623-1628.

-6 Ciralik H, Bulbuloglu E, Cetinkaya A, et al: Effects of $\mathrm{N}$-acetylcysteine on methotrexateinduced small intestinal damage in rats. Mt Sinai J Med 2006;73:1086-1092.

7 van't Land B, van Beek NM, van den Berg JJ, et al: Lactoferrin reduces methotrexate-induced small intestinal damage, possibly through inhibition of GLP-2-mediated epithelial cell proliferation. Dig Dis Sci 2004;49: 425-433.

8 Jahovic N, Sener G, Cevik H, et al: Amelioration of methotrexate-induced enteritis by melatonin in rats. Cell Biochem Funct 2004; 22:169-178.

-9 Gao F, Nakamaru M, Masubuchi Y, et al: Protective effect of a synthetic analog of prostaglandin $\mathrm{E}(1)$ on the small intestinal damage induced by the administration of methotrexate to rats. J Pharm Sci 2001;90:1040-1048.

10 Horie T, Matsumoto H, Kasagi M, et al: Protective effect of aged garlic extract on the small intestinal damage of rats induced by methotrexate administration. Planta Med 1999;65:545-548.

11 Yuncu M, Eralp A, Koruk M, et al: Effect of vitamin A against methotrexate-induced damage to the small intestine in rats. Med Princ Pract 2004;13:346-352.

12 Garg A, Garg S, Zaneveld LJ, et al: Chemistry and pharmacology of the citrus bioflavonoid hesperidin. Phytother Res 2001;15:655-669.

13 Akiyama S, Katsumata S, Suzuki K, et al: Dietary hesperidin exerts hypoglycemic and hypolipidemic effects in streptozotocin-induced marginal type 1 diabetic rats. J Clin Biochem Nutr 2010;46:87-92.
14 Galati EM, Monforte MT, Kirjavainen S, et al: Biological effects of hesperidin, a citrus flavonoid. (Note I): antiinflammatory and analgesic activity. Farmaco 1994;40:709-712.

15 Kawaguchi K, Kikuchi S, Takayanagi K, et al: Colony stimulating factor-inducing activity of hesperidin. Planta Med 1999;65:365-366.

16 Olszanecki R, Gebska A, Kozlovski VI, et al: Flavonoids and nitric oxide synthase. J Physiol Pharmacol 2002;53:571-584.

17 Chen YC, Shen SC, Lin HY: Rutinoside at C7 attenuates the apoptosis-inducing activity of flavonoids. Biochem Pharmacol 2003;66: 1139-1150.

18 Wilmsen PK, Spada DS, Salvador M: Antioxidant activity of the flavonoid hesperidin in chemical and biological systems. J Agric Food Chem 2005;53:4757-4761.

19 Sugiyama A, Kimura H, Ogawa S, et al: Effects of polyphenols from seed shells of Japanese horse chestnut (Aesculus turbinata BLUME) on methotrexate-induced intestinal injury in rats. J Vet Med Sci 2011;73:673-678.

20 Leitão RF, Brito GA, Oriá RB, et al: Role of inducible nitric oxide synthase pathway on methotrexate-induced intestinal mucositis in rodents. BMC Gastroenterol 2011;11:90.

21 Brandt E, Colombel JF, Ectors N, et al: Enhanced production of IL-8 in chronic but not in early ileal lesions of Crohn's disease (CD). Clin Exp Immunol 2000;122:180-185.

22 Taminiau JA, Gall DG, Hamilton JR: Response of the rat small-intestine epithelium to methotrexate. Gut 1980;21:486-492.
23 Yáñez JA, Teng XW, Roupe KA, et al: Chemotherapy induced gastrointestinal toxicity in rats: involvement of mitochondrial DNA, gastrointestinal permeability and cyclooxygenase-2. J Pharm Pharm Sci 2003;6:308-314.

24 Babiak RM, Campello AP, Carnieri EG, et al: Methotrexate: pentose cycle and oxidative stress. Cell Biochem Funct 1998;16:283-293.

25 Gerdes J, Li L, Schlueter C, et al: Immunobiochemical and molecular biologic characterization of the cell proliferation-associated nuclear antigen that is defined by monoclonal antibody Ki-67. Am J Pathol 1991;138:867873.

26 Kolli VK, Abraham P, Rabi S: Methotrexateinduced nitrosative stress may play a critical role in small intestinal damage in the rat. Arch Toxicol 2008;82:763-770.

27 Sakata K, Hirose Y, Qiao Z, et al: Inhibition of inducible isoforms of cyclooxygenase and nitric oxide synthase by flavonoid hesperidin in mouse macrophage cell line. Cancer Lett 2003;199:139-145.

28 Kucharzik T, Hudson JT 3rd, Lügering A, et al: Acute induction of human IL-8 production by intestinal epithelium triggers neutrophil infiltration without mucosal injury. Gut 2005; 54:1565-1572.

29 Yeh CC, Kao SJ, Lin CC, et al: The immunomodulation of endotoxin-induced acute lung injury by hesperidin in vivo and in vitro. Life Sci 2007;80:1821-1831.

30 Moon PD, Kim HM: Antiinflammatory effects of traditional Korean medicine, JinPitang and its active ingredient, hesperidin in HaCaT cells. Phytother Res 2012;26:657-662. 